\title{
Rethinking the Implications of the Patriarchic System of Male Dominance and Female Subordination in the Twenty First Century
}

\author{
Nde Paul Ade \\ Department of Philosophy, University of Bamenda, Bamenda, Cameroon
}

Email address:

icare4unde $@$ yahoo.com

\section{To cite this article:}

Nde Paul Ade. Rethinking the Implications of the Patriarchic System of Male Dominance and Female Subordination in the Twenty First Century. International Journal of Sustainability Management and Information Technologies. Vol. 5, No. 1, 2021, pp. 1-6. doi: $10.11648 /$ j.ipa.20210501.11

Received: January 11, 2021; Accepted: January 18, 2021; Published: April 20, 2021

\begin{abstract}
The ideology and practice of patriarchy and female dominance in the twenty first century constitute a major impediment to women's enhancement and progress. This study unveils the origins, meanings, nature, implications, and perspectives of patriarchic societies on the female gender and how these aspects influence their attitudes and development. Various forms of economic, political, social, and religious discrimination were generated against women from the past decades till present day. The forms of domination range from male children preference to female children, household chores, food distribution, unequal educational opportunities, wife battering, sexual harassment, discrimination on inheritance issues and ownership of property such as lands, houses, titles. It explores the experiences of women considered as victims of patriarchy and subordinates to men. It is of primordial necessity to understand why and how female domination and subordination manifests in order to ensure women's development systematically. Feminism could be understood from varied view points since there exist a multifaceted structure of feminisms. Feminism motivates and rekindles the anxiety for one to develop more interests on how female power mongers, especially, manifest their desires to occupy posts of responsibility, politically, socially, culturally, historically, and even economically. In brief, it balances the perennial needs, theoretical frameworks and creates a more enabling environment for the understanding and functioning of various structures of the society in a gendered pattern, since it advances from theory to practice. Patriarchy is one of the setbacks for women's progress in the society, since it guarantees absolute power for men in particular and establishes an inferior status for the female gender as a whole.
\end{abstract}

Keywords: Feminism, Men, Patriarchy, Domination, Cameroon, Female Subordination

\section{Introduction}

Gender equality debates and discussions have been going on for decades now, but the fight against women domination by men still persists, especially concerning issues connected to leadership as stated by Marsh Sheffler [1]. The underdevelopment of many third world countries is partly due to the exclusion of one of both genders in the daily activities of the society. No nation can boost of being developed or developing without the contribution of women. For instance, nowadays, women occupy the positions of queens, presidents, prime ministers, ministers, governors, mayors, judges and parliamentarians. Despite these positions, the system is still "male dominated" in virtually all human societies, although women are accommodating men in their various duties [2]. The purpose of this study is to explore the idea and practice of patriarchy and female subordination, the origins and reasons for female subordination and the manner in which husbands usually discriminate against their wives and daughters, stakes and perspectives of this plaguing issue are of primordial importance. This evocation of patriarchy and women subordination in this study will certainly provoke more debates and academic discussions on the issues in the near future, presently, academic debates on these ideologies and practices are either very rare, or almost absent in the academic scene. 


\section{Methodology}

This research helps to resurrect and illuminate feminism through feminist theories, examples, and evidence of subordination and men's domination of the women by adopting analytical approaches to the study. According to the feminist standpoint theory, aimed at creating awareness on the pride and role of women and their experiences, [3] and the contribution of women as the guarantors of social order as Harding [4] indicates that, feminism gives shape to knowledge and diversity. A majority of data collected during this research constituted the identification of cases or victims of female subordination, gathering of information and analyzing them from one case to the next, as well as following up discussions about the topic.

\section{Result and Discussion}

The goal of this paper was to explore the extent to which the idea and practice of patriarchy and female subordination are still plaguing issues of ongoing interest, thereby justifying the urgency to identify and resolve such contemporary challenges, as well as offering new insights into the subject matter. Embarking on this crucial and sensitive contemporary study gives room for future research, as a more thorough examination of the implications involving patriarchy and female subordination is historically, theoretically, and critically analyzed. Historically situating this perennial problem of gender bias and its relevance today is an additional research endeavor that contributes in enhancing freedom, equality, gender balance and human rights, not leaving aside the promotion of women's movements as the experiences in this twenty first century portray. Initially, women were those who had as part of their duties to shop for their families while the men use to work out of the house on daily basis.

Evidences supporting the enhancement and empowerment of women date back from the end of the first and second world wars, when women were granted the opportunity to work far from their homes for the first time. In addition to this, due to their interaction with other women, new skills were developed, women's rights were championed and propagated, alongside capitalism, as women continued the quest for income, power, and influence, so as to position themselves by improving on their progressive pace in the society. Surprisingly, according to the global professional services firm, the global incomes of women has grown up to $\$ 18$ trillion from 2018 and is still on the rise "Women are the world's most powerful consumers and their impact on the economy is growing every year".

That notwithstanding, despite the rise in economies stemming from the active and effective role of women, environmental hazards have contributed enormously to halt capitalism as resources are affected negatively by nature, thereby resulting to abnormalities in the outcome and output from the workforce.

\section{The Underpinnings and Meaning of Patriarchy}

Traditionally, it is believed that men are born to dominate women, and women are destined to be subordinate to men irrespective of age and social status. This belief has existed since time immemorial and could still continue existing just like other laws of nature that are unchangeable. Other opinions hold the view that, patriarchy is man-made and not a natural practice, so, it is liable to change. Similarly, Aristotle justifies the natural character of patriarchy when he describes men as "active", while referring to women as simply "passive". For him, a female refers to a "mutilated male", that is, someone without a soul. This inferiority of women is visible from their inability to reason correctly and take right decisions which contribute to qualify men as rulers and superior while regarding women as the ruled and inferior respectively. This superiority is expressed by Learner [5], when he writes, "The courage of a man is portrayed when he commands a woman and she obeys". Even Freud [6] states that, the only normal being by nature is the male sex because the anatomy of women is determined by destiny.

Another contribution to the origin of patriarchy is advanced by Engels [7], in his work titled The Origins of the Family, Private Property and the State, in which he reveals that the historical overthrow of the female sex started with the introduction and the growth of private property. This means that, the woman's place was excluded as men intended to preserve power and property in order to pass them on to their children, precisely male children, so as to ensure inheritance when they journey to the world beyond. For the radical feminists, patriarchy existed before the introduction of private property since they think that, the differences exist between sex and not among economic classes as advanced by Brownmiller [8] and Firestone [9]. To Hartman [10], patriarchy is connected to capitalism since a woman's work favors both capital and her husband which result to the domination of men over women, given that, men usually control women's labor, power, and force.

The term "Patriarchy" denotes a patriarch. It literally refers to the rule of a father. It was also a term applied to describe a family dominated by a man. In a patriarchic society, the family used to constitute slaves, women, domestic servants, younger men, who were all answerable to, and commanded by the dominating and dominant male. Nowadays, the word patriarchy has taken a different signification as it is understood and generally used to mean male domination both in the public and private sectors of the society. In this system, women are usually subordinated through various ways as Bhasin [11] confirms. Patriarchy goes beyond a term because feminist's analysts use it to describe the different forms of power relationships existing among men and women. It equally signifies a system of kinship characterized by the exchange of women by men [12].

It also refers to "a system of dominant structures and practices in which men dominate, oppress and exploit women" [13]. This meaning is intended to condemn the idea of 
biological determinism that reveals the different roles to be played by men and women since their bodies are different as well. In a nutshell, patriarchy is understood as a demonstration of male dominance over women and the institutionalization of vertical power relationships between a man and a woman, creating solidarity among men that permits them to dominate women easily as confirmed by Jagger [14] and Rosenberg, [15]. Male domination on women is visible in families, schools, churches, characterized by competition, hierarchy, oppression, exploitation that lead to women's subordination [16].

\section{The Underpinnings and Significations of Female Subordination}

Almost all aspects of life are characterized by female subordination to men as evidence from the family, society and the state portray the power and authority men exercise over women. This is exemplified through the restriction of women from enjoying their legal rights, mobility, freedom and ownership of property. To Cobuild [17], the term "Subordination" is understood as "something else that is less important than the other thing". The Advanced Learners Dictionary states, "subordination means having less power or authority than someone else in a group or organization" [18]. From these analyses, "Female subordination" therefore, could be understood as the inferior role played, and position occupied by the female gender, especially women as far as decision making concerning societal issues is concerned. The factors that result to the subordination of women by men range from the feeling of low self-esteem, powerlessness, absence of self-confidence and discrimination at various levels.

Moreover, female subordination is a condition where women are dominated by men in relationships and state affairs. Another justification by contemporary feminist thinker, Simone de Beauvoir [19] attest that, men consider women as subordinates because they are second sex beings in terms of status and see themselves (men) differently from them (women). This explains why women are always fertile grounds for insults, violence, rape, disrespect, oppression, control, exploitation, discrimination, both at the family level and the society in general. Presently, evidences of female subordination are visible everywhere within the family, religious doctrines and laws, schools, medias, textbooks, offices, social relationships and in factories. Because men regard women as "objects" or property, they tend to treat them inhumanely and this leads to female subordination. Gerda Learner in the text The Creation of Creation of Patriarchy, believes that, the coinage "subordination" is better than the term "oppression" in the sense that, subordination does not necessarily carry an evil intention by the man dominating since the woman approves and gives her consent for a subordinate status in order to gain protection and privileges such as marital status and societal respect.

In this subordinate situation, one person is obliged to be submissive enough to permit the other (man) to control her. To intensify this, the society through customs and traditions has prescribed certain norms so as to safeguard male supremacy over women by distinguishing between masculine and feminine characteristics and duties. Through such distinction and system of patriarchy and subordination in the family, religion, political, social and economic systems, the power, labor, sexuality, reproduction, movement and property of a woman are surrendered to the man for patriarchic control. That is why subordination could be considered synonymous to "paternalistic dominance" which does not denote evil intent.

\section{The Objections to Patriarchy and Subordination}

A critical study of patriarchy and female subordination indicates that, there is a relationship between these practices, exploitation and capitalism. This is evident because men always benefit materially and financially from women due to their subordination to men in a patriarchic system. In this situation, the house wives are the productive force to their husbands, the family, and the society. Unfortunately, the back breaking and tireless activities of women labor are never or rarely appreciated by men or the society in which they belong. This portrays the material foundation of patriarchy, including the fact that, resources and property are usually under the control of men, who pass them on from one generation to the other especially to their male children [20]. Some challenges preventing women from inheriting property include social punishments, violence, customs and traditions, pressure from in-laws and emotional pressures.

Similarly, following the intention to enhance patriarchy and female subordination by men, two forms of power manifestation systems have been put in place for women and men. These two systems coined "private" and "public" are meant to classify the real position of both men and women in a patriarchy. The private focuses on household production and activities of the women as an example of a center of oppression. Here, women exploitation takes place mainly by the individual or the man in a particular household. The public realm which concerns the public sites like job sites and the state as a whole, manifests collective expropriation and subordination of women. Within the public sphere, men use various forms of violence to dominate and subjugate women which authorities often portray reluctance to intervene or react to. Examples of such violence include: incest, rape, wife battering, sexual harassment, murders, which lead to insecurity and render women inferior, weak, socially and economically exploited and exploitable in the society.

The mindset of contemporary society has equally intensified the patriarchic system by their behavior, thinking, and goals about life that are always linked to the idea of masculinity and "feminity" opened to various types of bias through the establishment of differences. According to this 
distinction, the different sexes have different characteristics, such as, men are endowed with strength, courage, boldness, bravery, fearlessness and competition, whereas, women are qualified as caring, loving, timid, obedient, submissive, soft hearted and naïve. Also, within the household set up, women are believed to do more work than men, irrespective of whether they are also employed elsewhere and are paid. Hartman states that, both household chores and wage employment are vital avenues for the continual exploitation of women by men.

\section{Evidences of Female Subordination Among the "Nordese" Women in Cameroon}

Segregation, exploitation, inequality and disrespect against the female gender in general constitute an obstacle to the peace and development of a nation and a gross violation of human rights, especially the rights of a girl child or female. The social system of the customs and traditions of the Northerners in the Grand Nord part of Cameroon comprising; Extreme North, North, and Adamawa, constitute a fertile case study of women subordination and men domination and suppression. In these regions, women are a prey to virtually all forms of domination by men at the cultural, political, social, economic, religious and traditional levels which eventually produce female subordination. This patriarchic system is illustrated by the practice of paying a bride price for a female who is underage or immature (Usually between the ages of 2 to 5 years old) by the husband to be. Worst of all, in some cases, despite the tender age and innocence of the child, tradition permits the husband to bring up the girl child (wife) the way he deems fit and necessary since the child is traditionally betrothed to him.

Similarly, the practice of widows forced to continue living with the relatives of the deceased husband is an indicator of female subordination. Sometimes, such widows are obliged to marry the brother or relative of the deceased husband against her wish and without seeking her opinion. Moreover, even the practice of living with the husbands relatives after marriage (patrilocal residence), is a violation of the rights of women which is also a common phenomenon among the northerners of Cameroon. All these cases influence the position of women in the society as it emphasizes on masculinity or the male child as the one to inherit the family property and uphold the family name, while the girl is described as worthless and treated as subordinate to the male child. This preferential treatment is derived from the belief that, girls are a source of load to parents since they will one day go to their various husbands' houses and join a new family while the male children are the ones to always remain in the family to take care of their parents. From these premises, the subordination of women begins from her first family background as these discriminatory systems are put in place from a tender age of the girl. Even in her husband's house she is subordinated and oppressed, thereby destroying her self-respect, confidence and goals.

\section{General Outlook of Male Dominance in Cameroon}

Generally, examples of women subordination and patriarchic systems are manifested everywhere, as people usually prefer to produce male children than female. This choice is due to the belief system of the communities that, male children are more valuable because they are the ones to inherit property and keep the family name after their parents must have died. Even at the level of food distribution in the family, men are always served more food than women and women are the ones who serve men, wash dishes, cook and undertake other household tasks. Also, some societies still believe that, the education of a girl child is meaningless, thereby depriving them of educational opportunities and the numerous advantages that education of a female could have offered.

Mobility of women is often restricted or prohibited by men as a characteristic of patriarchy. This practice of locking women in the room before leaving the house by men, or the act of preventing women from going out to work, meeting with their friends or relax is very common among the Muslim communities who believe that, going out or exposing part of a woman's body goes against the teachings of Islam and should be proscribed for women. Wife battering is also a component of female subordination experienced in Cameroon. In some cultures such as the Betis, any man who does not beat his wife regularly implies that he does not love her. Therefore, wife battering, though painful and may lead to death is culturally justifiable as a "sign of true love the husband has for his wife".

Girls and women are sexually harassed by their bosses, teachers, and colleagues as a characteristic of patriarchy. Many women loss their jobs, female students fail their exams or earn very low marks, some are insulted, humiliated, threatened and rejected if they do not give in to the quests of the men working with them or for them. Even married men believe they have full control over the wife's sexuality no matter the health condition of the woman, and also decide on family planning by being the ones (men) to determine the number of children to have, and to an extent deciding the sexes of the children to be born of the woman. To add, parents or the men are often the ones to choose husbands for their daughters and impose their choices on the women, still, when women get married, they are prohibited from supporting their relatives through various ways. To Nde Paul [21], this partly explains the poverty, landlessness and illiteracy that define most rural poor women like the case of the women in the northern part Cameroon.

\section{Perspectives}

In order to improve on the treatment meted on women for several decades, it is vital to encourage women, especially 
those who have indicated concern for women's plight such as the feminist's thinkers to be part of the leadership process of the citizens. Their presence as leaders will certainly guarantee gender equality at every level and enhance social change. Moreover, the creation of women's movements and promoting their visions will drastically reduce or completely eradicate the poor treatment and domination by men, since awareness through education is going to play a catalyst role in fostering learning and shaping their experiences better [22].

Discussions, debates, conferences, seminars, centered on the problems and pressure women undergo in their daily lives are supposed to be put in place in all the sectors of the state machinery. With this, gender bias, male domination, and female subordination will be far-fetched. The intensification of women and gender studies influences feminists' identity and expectations which produce positive change and creates a remarkable impact in their lives and aspirations. This is attainable in a case where women are given posts of command and decision making in the affairs of the society and the nation as a whole. Through this means, various identities will be better understood, protected, guaranteed and promoted to foster development.

\section{Conclusion}

In sum, from the above analysis, it is obvious that women undergo different forms of subordination and have been subordinated victims since time immemorial as evidences from their experiences portray [23]. This subordination mostly derived from male domination is exploitative in nature and characterized by the existence of unequal pay when the same job is concerned, low wages for women, oppression through violence such as wife battering, discrimination of various sorts including the preference to have male children instead of female children, the load of household work with the majority attributed to girls and women, lack of education for the girl child, lack of freedom of movement, association and speech, the negative picture usually painted concerning women by the media, among others, confirm the gross manifestation of female subordination on the one hand, and male dominance on the other hand.

Although the Cameroon laws guarantee and protect the rights of women and girls, female subordination still persists in the social, political, economic and legal spheres of the society as patriarchal practices still manifest at various levels. This subordination of women by men result from the interpretation men give about religion and tradition, which, to them, give them the full rights to exercise their domination and authority over women as "heads of the family". To eradicate this patriarchic belief, it is necessary to define the roles of men and those of women, rights, and responsibilities of each party. Whether male or female, masculine or feminine, we are all humans, so, there is no tangible reason that justifies the differentiation of sex, rights, roles, duties, responsibilities, etc. This differentiation originates principally from the selfish interests of men who intend to acquire material gains from the women's labor.

Culturally, only boys or men are trained and programmed to succeed in life since the female does not enjoy equal privileges with the male child fashioned to flourish and succeed the family. If men start playing the role formerly thought to be reserved for women only, such as, if men start by looking after children while the women engage in other things, taking care of the household by washing plates, cooking, cleaning, babysitting, then, they will certainly learn to be more caring, more understanding, more sensitive and more gentle, which will relieve the burden women usually carry. Women should also make an effort to exercise "male traits" like bravery, courage, fearlessness and rationality, as well as practice them. Again, the moral aspects of religion and the law should be scrutinized and reformed to suit the needs of gender equality and insubordination of one class by the other [24].

Lastly, this is the moment for a drastic change to be experienced as far as man-woman, boy-girl relationships are concerned in order to completely uproot patriarchy, male dominance, and female subordination from the retarding the growth of the society. Equal rights and responsibilities should be implemented for both men and women, that is, women should also be given the right to own and inherit lands, houses, property and be treated equally like men at every level of involvement and interaction, be it at the family, employment, payment, religion, culture, leadership or in politics and decision making levels.

\section{References}

[1] Marsh, S. C. (2017). The Fearless Girl Statue Sums up What's Wrong with Feminism Today, The Guardian. www.the guardian.com/film/2017/mar/12/emma-watson-feminist-orpolished-brand. Accessed 18 Dec. 2020. Web.

[2] Neff, J. (2017). Top Ad Campaigns of the $21^{\text {st }}$ Century, AdAge, adage.com/lp/top 15/intro. Accessed 20 Dec. 2020. Web.

[3] Hartstock, N. (1983). The Feminist Standpoint. In S. Harding \& M. B. Hintikka (Eds.), Discovering Reality, Boston, MA: Riedel, pp. 283-310.

[4] Harding, S. (1993). The Racial Economy of Science: Toward a Democratic Future, Bloomington, IN: Indiana University Press.

[5] Learner, G. (1989). The Creation of Patriarchy. Oxford University Press: New York.

[6] Freud, S. (1977). On Sexuality. Harmondsworth: Penguin.

[7] Engels, F. (1940). The Origin of the Family, Private Property and the State. London: Lawrence and Wishart.

[8] Brownmiller, S. (1976). Against Our Will: men women and rape. Harmondsworth: Penguin.

[9] Firestone, S. (1974). The Dialectic of Sex: The case for feminist revolution. New York: Morrow. 
[10] Hartmann, H. I. (1981). The Unhappy marriage of Marxism and Feminism: Toward a more progressive union, in Women and Revolution, London: Pluto Press, pp. 95-119.

[11] Bhasin, K. (2006). What is Patriarchy? Women Unlimited: New Delhi.

[12] Mitchell, J. (1971). Women's Estate. Harmondsworth: Penguin.

[13] Walby, S. (1990). Theorizing Patriarchy. Blackwell Publishers Ltd.: Oxford, UK and Cambridge, USA.

[14] Jagger, M. A. \& Rosenberg, S. P. (1984). Feminist Frameworks. New York: MC Grew-Hill.

[15] Rosenberg, S. P. (1984). Feminist Frameworks. New York: MC Grew-Hill.

[16] Millett, K. (1977). Sexual Politics. London: Virago.

[17] Cobuild, C. (2010). Advanced Illustrated Dictionary. Harper Collins Publishers Ltd.: Great Britain.

[18] Hornby, A. S. (2003). Oxford Advanced Learners Dictionary. Oxford University Press: New York.
[19] Beauvoir, D. S. (1974). The Second Sex. Vintage Books: New York.

[20] Tolentino, J. (2017). The Case Against Contemporary Feminism, The New Yorker, www.newyorker.com/books/page-turner/the-case-againstcontemporary-feminism. Accessed 29 Dec. 2020. Web.

[21] Paul, N. (2020). The Pedagogic Relevance of Alobwed' Epie's The Death Certificate to High School Students in Cameroon: A Thematic Approach, International Journal of New Economics and Social Sciences, 1, II, pp. 361-376.

[22] Womens March on Washington.@womensmarchonwash. Facebook Post. Mar. 8, 7:02 am. Accessed 1 Nov. 2020.

[23] Edelstein, J. H. (2017). Emma Watson: Feminist to the Core or a Carefully Polished Brand? The Guardian, www.theguardian.com/film/2017/mar/13/emma-watsonfeminist-or-polished-brand. Accessed Nov. 2020. Web.

[24] Monsoor, T. (1999). From Patriarchy to Gender Equity: Family Law and its Impact on Women in Bangladesh. The University Press Limited: Dhaka. 